\title{
Impact of Equine Chorionic Gonadotropin Associated with Temporary Weaning, Estradiol Benzoate, or Estradiol Cypionate on Timed Artificial Insemination in Primiparous Bos Indicus Cows
}

\author{
Andre Luis Bastos Souza ${ }^{1}$; Marcio Saporski Segui ${ }^{1}$; Luiz Ernandes Kozicki ${ }^{*}$; Romildo \\ Romulado Weiss ${ }^{1}$; Ana Abreu ${ }^{1}$; Melina Andreia Formighieri Bertol ${ }^{1}$; Danilo Martins \\ Amadori Oliveira ${ }^{2}$ \\ ${ }^{1}$.Pontifica Universidade Católica do Paraná, Medicina Veterinária, Curitiba, Paraná, Brasil, ${ }^{2}$ Pontificia \\ Universidade Católica do Paraná, Curitiba, Paraná, Brasil.
}

\begin{abstract}
The study aimed to determine the impact of equine chorionic gonadotropin (eCG) associated with different timed artificial insemination (TAI) protocols on the pregnancy rate (PR) in Bos indicus cows previously treated with progesterone. Five hundred and fifty-seven primiparous cows were subjected to the following treatments: on day 0 (d0), GeCGTW (group equine Chorionic Gonadotropin + Temporary Weaning; $n=178$ ) received 0,558 $g$ intravaginal progesterone (P4)+1.0 mg of estradiol benzoate (EB) (IM); on d8 (P4 removal +0,075 mg D-cloprostenol $+400 \mathrm{IU}$ $e C G+T W$ for $48 \mathrm{~h}$ ); on d10, TAI + calves return to dam; GeCGEB (group equine Chorionic Gonadotropin+Estradiol benzoate; $n=176)$ the same as GeCGTW without $T W+$ application of $1.0 \mathrm{mg}$ of EB on d9; GeCGEC (group equine Chorionic Gonadotropin+Estradiol Cypionate; n=203), the same as GeCGTW without $T W+1.5 \mathrm{mg} E C(I M)$. On d35, post TAI, pregnancy diagnosis (PD) was performed. Non-pregnant animals remained under clean-up bulls for 90 days. After this period, the animals were subjected to PD using ultrasound. The PR of TAI was $51.1 \%, 47.1 \%$, and $47.8 \%$ for GeCGTW, GeCGEB24, and GeCGEC (P>0.05) respectively. The PR under clean-up bulls was $88.3 \%, 47.3 \%$, and $31.1 \%$ (P<0.05). The final PR (TAI+clean-up bulls) of the groups was $94.4 \%, 72.1 \%$, and $64.0 \%$, respectively $(P<0.05)$. It was concluded that no differences in PR among the protocols related to TAI were detected; PR in the GeCGTW protocol under clean-up bulls was higher compared to others $(P<0.05)$; the overall PR of cows subjected to TAI+clean-up bulls was significantly higher in GeCGTW than in the other groups.
\end{abstract}

Key words: Beef catlle, Equine Chorionic Gonadotropin, Fixed time artificial insemination.

*Corresponding Author: kozicki.1@pucpr.br 
Kozicki, LE et al.

\section{INTRODUCTION}

Although conventional artificial insemination (AI) has become one of the most efficient reproductive biotechnologies, resulting in significant benefits to cattle herds, it is not been widely used in tropical countries (Barreiros et al. 2014). Some limitations of its applicability on a large scale include the necessity of daily observations for estrus detection, low cyclicality rate, low service rate in cows after calving, and workforce shortage. Researchers have been conducting studies to improve and overcome the challenges of AI by adopting timed artificial insemination (TAI). This biotechnology not only provides the advantages of conventional AI, but also includes other benefits such as the ability to perform AI in a large number of animals without estrus observation, and the relatively short duration (Sales et al. 2015).

Many hormonal protocols related to TAI have been developed for beef cattle in the last decade by using long-acting progesterone $\left(\mathrm{P}_{4}\right), \mathrm{EB}$, or gonadotropin-releasing hormone $(\mathrm{GnRH})$ on the first day of treatment (Pursley et al.1995; Wheaton and Lamb 2007), followed by eCG, $\mathrm{EC}$, or even temporary weaning (TW), when the intravaginal $\mathrm{P}_{4}$ is removed (day 8 after the start of the protocol) (Campos et al. 2013; Barreiros et al. 2014).

To improve ovarian follicle quality, ovulation, and pregnancy rate (PR), eCG was administered on the day of $\mathrm{P}_{4}$ removal in TAI protocols (Peres et al. 2009; Sá Filho et al. 2010; Campos et al. 2013). Peres et al. (2009) reported the enhancing effect of eCG on serum $\mathrm{P}_{4}$, ovulation, and $\mathrm{PR}$ in non-lactating Bos indicus cows. Small et al. (2009) determined the effects of estrus presynchronization using intravaginal $\mathrm{P}_{4}$ and eCG at $\mathrm{P}_{4}$ removal stating that eCG had no significant effect on the diameter of the preovulatory follicle, but signaled improved PR in primiparous cows. Sá Filho et al. (2010) established positive eCG effects (increased growth rate of the largest follicle, larger follicle diameter, increased ovulation rate, and increased $\mathrm{PR}$ ) after $\mathrm{P}_{4}$ removal in TAI in Nellore cows.

To improve reproductive efficiency several protocols for TAI have been proposed, including eCG and TW. Soto Belloso et al. (2002) administered $\mathrm{P}_{4}$ plus eCG or TW to induce fertile estrus, reduce the interval between estrus, and lower birth-conception interval in anestrus B. indicus cows. Meneghetti et al. (2009) conducted studies in a commercial herd aiming to develop a protocol for TAI, to reach a PR of $40 \%$ to $55 \%$ in B. indicus cows. They concluded that the TAI protocols should contain $400 \mathrm{IU}$ eCG associated with TW.

The combination of eCG and TW in Bos indicus lactating cows was also used for estrus resynchronization. Campos et al. (2013) verified that the association between eCG and more TW was the best protocol for TAI in $B$. indicus lactating cows.

For induced ovulation studies, EC was administered at the time of $\mathrm{P}_{4}$ removal. This resulted in ovulation between $67 \mathrm{~h}$ and $70 \mathrm{~h}$ after treatment (Sales et al. 2008). Penteado et al. (2006) administered EC to B. indicus lactating cows on the day of $\mathrm{P}_{4}$ removal, resulting in $49.4 \% \mathrm{PR}$, indicating that it can be used on the day of $\mathrm{P}_{4}$ removal. Sales et al. (2012) synchronized ovulation in $B$. indicus cows using EB or EC. They concluded that both esters effectively induced a preovulatory LH peak resulting in synchronized ovulation either by applying EC on $\mathrm{P}_{4}$ removal or EB $24 \mathrm{~h}$ after $\mathrm{P}_{4}$ removal. Sá Filho et al. (2011) administered EC at $\mathrm{P}_{4}$ removal, resulting in improved ovarian response due to greater follicles in TAI, higher ovulation rate, biggercorpus luteum, higher $\mathrm{P}_{4}$ concentration and more efficient PR. The hypothesis of this study is that primiparous cows treated with a protocol of eCG and TW of a 48-h duration (previous treatment $\mathrm{P} 4$ ), could result in higher PR at the end of the breeding season, than the protocol EB $48 \mathrm{~h}$ after the application of eCG or EC on the same day.

This study aimed to determine the impact of eCG followed by TW for $48 \mathrm{~h}$; eCG followed by EB $24 \mathrm{~h}$ after or eCG more estradiol cypionate in the same day, in primiparous $B$. indicus cows previously subjected to an intravaginal device with long-acting $\mathrm{P}_{4}$ on the $\mathrm{PR}$ in the postpartum period. 


\section{MATERIAL AND METHODS}

\section{Selection, management, and feeding of animals}

We used 557 primiparous $B$. indicus cows (Nellore breed) from a commercial farm, with an average age of 36 months, body condition score $(\mathrm{BCS})=2.8 \pm 0.4$ (2.0 to 4.0 , considering $1=$ thin, $5=$ obese), $64 \pm 20.1$ days open after delivery (30-112 days), $320 \mathrm{~kg}$ average weight. The animals grazed on Brachiaria brizantha, with provision of mineral salt and water ad libitum. The cows, were divided in groups, subjected to the same management, and inseminated in the same day. Pregnancy was performed by use of ultrasound machine (Tringa Ultrasound model, 5-MHz transducer; Pie Medical, Netherlands) on day 35 after TAI and after 90 days of the breeding season period. On day 35, non-pregnant animals remained in the same groups along the breeding season $(90$ days) for clean-up bulls in the proportion of one bull for 20 cows. Before the clean up of the bulls, semen analysis according to the rules of the CBRA (1998) was performed.

\section{Experimental design}

The animals were assigned into three groups $(\mathrm{G})$ and subjected to the following protocols (Fig.1): GeCGTW48 (Group eCG+ Temporary Weaning=calf separated out of dam for 48 hours; n=178); GeCGEB24 (eCG + estradiol benzoate $24 \mathrm{~h}$ after $\mathrm{P}_{4}$ removal; $\left.\mathrm{n}=176\right)$ and GeCGEC (eCG + estradiol cypionate; $\mathrm{n}=203$ ).

GeCGTW (Group Equine Chorionic Gonadotropin + Temporary Weaning) $(n=178)$

\begin{tabular}{|c|c|c|c|c|}
\hline EB & $-\mathrm{P}_{4}+\mathrm{PGF}_{2 \alpha}+\mathrm{eCG}+\mathrm{TW}$ & $\mathrm{TAI}+\mathrm{CR}$ & $1^{\mathrm{st}} \mathrm{PD}$ & $2^{\text {nd }} \mathrm{PD}$ \\
\hline & $\mathrm{P}_{4}$ & $\uparrow$ & $\uparrow$ & $\uparrow$ \\
\hline $\mathrm{d} 0$ & $\mathrm{~d} 8$ & $\mathrm{~d} 10$ & d35 & d125 \\
\hline
\end{tabular}

GeCGEB (Group Equine Chorionic Gonadotropin + Estradiol Benzoate) $(n=176)$

EB

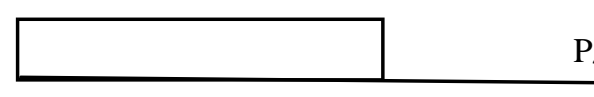

$\mathrm{d} 0$

$\mathrm{d} 8$

TAI

$1^{\text {st } P D}$

$2^{\text {nd }} \mathrm{PD}$

$\mathrm{P}_{4}$

d9

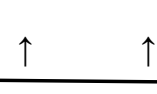

d10

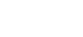

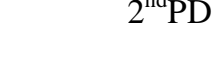

GeCGEC (Group Equine Chorionic Gonadotropin + Estradiol Cypionate) (n=203)

\begin{tabular}{|c|c|c|c|c|}
\hline EB & $-\mathrm{P}_{4}+\mathrm{PGF}_{2 \alpha}+\mathrm{eCG}+\mathrm{EC}$ & TAI & $1^{\text {st }} \mathrm{PD}$ & $2^{\text {nd }} P D$ \\
\hline & $\mathrm{P}_{4}$ & $\uparrow$ & $\uparrow$ & $\uparrow$ \\
\hline $\mathrm{d} 0$ & $\mathrm{~d} 8$ & $\mathrm{~d} 10$ & $\mathrm{~d} 35$ & d125 \\
\hline
\end{tabular}

Figure 1 -Graphical representation of applied protocols to groups of primiparous Bos indicus cows for timedartificial insemination $(\mathrm{n}=557)$; $\left(\mathrm{P}_{4}\right.$ - Cronipress monodosis -0.558 g progesteron= Cronipress, Biogenesis Bago); EB(Cronibest - $1 \mathrm{mg}$ estradiol benzoate, Biogenesis Bago); equine Chorionic Gonadotropin= 400 UI (Folligon, MSD - Animal health, São Paulo, Brazil); $\mathrm{PGF}_{2 \alpha}(0.075$ mg D-Cloprostenol - Croniben, Biogenesis Bago); EC (1.5 mg - Zoetis, São Paulo, Brazil); CR= calf return; $\mathrm{PD}=$ pregnancy diagnosis. 


\section{Statistical analysis}

Data related to the PR for TAI and to the cleanup bulls were compared using the chi-square test with Yates' correction $\left(\mathrm{X}^{2}\right)$ at $\mathrm{P}<0.05$ level of significance (Soft GraphPad Prism, version 5.0, 2014).

\section{RESULTS AND DISCUSSION}

In recent years, hormonal protocols related to TAI in cattle provided significant advances in the replacement of conventional AI. These studies have been addressed to an increased understanding of ovarian follicular dynamics, and hormonal reproductive physiology.

Primiparous suckling cows are a special class of animals, because they are more sensitive and more susceptible to nutritional imbalance along the postpartum period than pluriparous cows (Vasconcelos 2011). Primiparous cows are those that have recently passed from heifer to cow condition, an event that heavily affects the BCS (tendency to slimming), especially in beef cattle. One of the causes of this imbalance can be attributed to nursing, depleting essential nutrients in the primiparous cow (Short et al.1990; Wiltbank et al. 2002). Regarding this matter we hypothesized that the hormonal protocol eCG + TW would resulted in better PR than the other groups at the end of the breeding season. This was confirmed because GeCGTW demonstrated PR higher than the other groups $(\mathrm{P}=0.0001)$, related to the clean-up bulls and also to TAI + clean-up bulls in the final rate of the breeding season (Table 1).

Table 1 - Pregnancy rate (PR) in primiparous Nellore cows, related to timed artificial insemination (TAI) and cleanup bulls $(\mathrm{n}=557)$.

\begin{tabular}{|c|c|c|c|}
\hline Groups & $\begin{array}{l}\text { PR of TAI } \\
\quad(\mathrm{n} / \%)\end{array}$ & PR of clean-up bulls(n/\%) & $\begin{array}{c}\text { PR at end of } \\
\text { breeding season } \\
\text { (TAI+clean-up bulls) } \\
(\mathrm{n}-\%)\end{array}$ \\
\hline $\begin{array}{c}\text { GeCGTW } \\
(n=178)\end{array}$ & $92 / 178(51.7)$ & $76 / 86(88.3)^{\mathrm{a}}$ & $168 / 178(94.4)^{\mathrm{a}}$ \\
\hline $\begin{array}{c}\text { GeCGEB } \\
(\mathrm{n}=176)\end{array}$ & $83 / 176(47.1)$ & $44 / 93(47.3)^{b}$ & $127 / 176(72.1)^{\mathrm{b}}$ \\
\hline $\begin{array}{c}\text { GeCGEC } \\
(n=203)\end{array}$ & $97 / 203(47.8)$ & $33 / 106(31.1)^{\mathrm{c}}$ & $130 / 203(64.0)^{\mathrm{b}}$ \\
\hline $\begin{array}{c}\text { Total } \\
(n=557)\end{array}$ & $272 / 557(48.8)$ & $153 / 285(53.7)$ & $425 / 557(76.3)$ \\
\hline
\end{tabular}

Different letters in the same column are significantly different $(\mathrm{P}<0.05)$.

Over the last decade, PR in beef cows has varied greatly among studies related to TAI. PR may extend from 27.0\% (Peres et al. 2009), 42.4 (Hill et al. 2014), 49.6\% (Sá Filho et al. 2009), 50.7\% (Baruselli et al. 2012) to $62.4 \%$ (Dobbins et al. 2009). The results of the present study showed no differences between treatments applied in three groups of cows to TAI (table 1).

However our results (PR) of TAI in primiparous shown to be superior to Sá Filho et al. (2009) and Hill et al. (2014), which worked with Bos taurus indicus and Bos taurus taurus. On the other hand data from this study confirm very good results in PR when there wasclean up of the bulls for cows previously submitted to $\mathrm{P}_{4}$ and $\mathrm{EB}$ in the end of the breeding season, corroborating studies of Baruselli et al. (2012), which found strong increase in PR in cows pretreated with progestin and EB (Table 1). The $\mathrm{PR}$ at the end of the breeding season (results from TAI + clean-up bulls), GeCGWT showed differences $(\mathrm{P}<0.05)$ compared to other groups (22.3\% more than GeCGEB, and $30.4 \%$ more than GeCGEC). Studies confirm an increase of $15 \%$ to $20 \%$ in PR, by using TW associated with eCG towards protocols without TW in the other 
two groups (Barreiros et al. 2014). This result could be attributed to the TW itself. Increaseof the $\mathrm{GnRH}$ and $\mathrm{LH}$ pulses frequency, resulting in a higher ovulation rate, essential for good results in AI (Edward 1985).

Temporary weaning leads to a good combination of results increasing the fertility rate in $B$. indicus cows, stimulating LH secretion (Edward 1985). This mechanism can be optimized after eCG administration, increasing PR. Potentially eCG offers improvement in follicular development rate, and additionally provides more detailed $\mathrm{E}_{2}$ profiles during the proestrus and diestrus $\left(\mathrm{P}_{4}\right)$ phase, optimizing fertility (Sá Filho et al. 2009). The hypothesis of this study was that primiparous cows submitted to hormonal protocols with eCG + TW (48 h) after previous exposure to long-action P4 would result in better PR at TAI. Partly this happened because the group GeCGTW showed higher PR by bulls clean up alone and TAI + clean up at the end of the breeding season. In fact, this was confirmed because GeCGEB and GeCGEC displayed no differences between themself at the end of the breeding season (Table 1).Working on five groups of beef cows, Campos et al. (2013) administered $300 \mathrm{IU}$ eCG in one group and subjected the other group to eCG + TW, resulting in higher $\mathrm{PR}$, than in other groups using estrus resynchronization protocols. Yelich et al. (1995) used TW after the previous use of oral progestin. They found that $\mathrm{P}_{4}+\mathrm{TW}$ treatment was more effective than that in other groups, as well as TW + eCG that resulted in better PR rates (Sá Filho et al. 2010). B. indicus cows treated with norgestomet $+500 \mathrm{IU}$ eCG after removal of the implant, or treated only with TW $(96 \mathrm{~h})$ showed greater efficiency by reducing the estrus interval/first service, and increasing the conception rate (Soto Belloso et al. 2002). Cows milked twice daily without calves, presented a shorter duration between parturition/first estrus and additionally showed better reproductive efficiency than cows with suckling calves. The calf suckling action activates mechanisms that inhibit the hypothalamic-pituitary-ovarian axis of the cow after delivery for longer than 90 days (Soto Belloso et al. 2002). Although the mechanism of this process is not fully understood, the response of estrus depends partly on the number of follicles and their level of maturity when the calf is removed (Dunn et al.1985). Treatment with eCG at P4 removal increased conception rate in anestrus B. indicus cows (Baruselli et al. 2004; Sá Filho et al. 2004). Additionally, the use of eCG led to improve follicular development, increasing the $\mathrm{P}_{4}$ concentration in the luteal phase after ovulation (Sá Filho and Vasconcelos 2010). By application of eCG, B. indicus cows with small or medium follicle sizes, presented better PR (Cutaia et al. 2003; Baruselli et al. 2004), and ovarian cyclicity was induced, even when affected by nutritional factors (Bó et al. 2003), or under BCS adverse conditions (hard ovaries and small follicles) after delivery. In the present study the cows carried average BCS of 2.8. The eCG + TW may have contributed to a higher follicular development due to absence of endogenous opioids and the higher flushing of pituitary $\mathrm{FSH}$, than other groups of cows that received $\mathrm{eCG}+\mathrm{EB}$ or eCG + EC only. This provided a more effective and ovarian activity (cyclicity) and ovulation confirming the findings of Yelich et al. (1995).

\section{CONCLUSION}

The eCG + TW protocol was more efficient than the eCG + EB or eCG + EC, related to clean-up bulls, or TAI + clean-up bulls, at the end of the breeding season in primiparous cows.

\section{REFERENCES}

Barreiros TRR, Blaschi W, Santos GMG, Morottti F, Andrade ER, Baruselli, PS, et al. Dynamics of follicular growth and progesterone concentrations in cyclic and anestrous suckling Nellore cows (Bos indicus) treated with progesterone, equine chorionic gonadotropin, or temporary calf removal. Theriogenology. 2014; 81: 651-656.

Baruselli PS, Reis EL, Marques MO, Nasser LF, Bo GA. The use of hormonal treatments to improve reproductive performance of anestrous beef cattle in tropical climates. Anim Reprod Sci. 2004; 82-83: 479-486.

Baruselli PS, Sales JNS, Sala RV, Vieira LM, Sá Filho MF. History, evolution and perspectives of 
timed artificial insemination programs in Brazil. Anim Reprod Sci. 2012; 9:139-152.

Bó GA, Baruselli PS, Martinez MF. Patterns and manipulation of follicular development in Bos indicuscattle. Anim Reprod Sci. 2003;78:307-326.

Campos JT, Marinho LSR, Lunardelli PA, Morotti F, Seneda MM. Resynchronization of estrous cycle with eCG and temporary calf removal in lactating Bos indicus cows. Theriogenology. 2013; 80: 619623.

Cutaia L, Tribulo R, Moreno D, Bó GA. Pregnancy rates in lactating beef cows treated with progesterone releasing devices, estradiol benzoate an equine chorionic gonadotropin (eCG). Theriogenology. 2003; 59: 216.

Dobbins CA, Eborn DR, Tenhouse DE, Breiner RM, Johnson SK, Marston TT, et al. Insemination timing affects pregnancy rates in beef cows treated with CO-Synch protocol including an intravaginal progesterone insert. Theriogenology. 2009; 72: 1009-1016.

Dunn RT, Smith MF, Garverick HA, Foley CW. Effects of $72 \mathrm{~h}$ calf removal and/or gonadotropin releasing hormone on luteinizing hormone release and ovarian activity in postpartum beef cows. Theriogenology. 1985; 23: 767-776.

Edward S. The effects of short term calf removal on pulsatile LH secretion in the postpartum beef cow. Theriogenology. 1985; 23: 777-785.

Hill SL, Perry GA, Mercadante VRG, Lamb GC, Jaeger JR, Olson KC, et al. Altered progesterone concentrations by hormonal manipulations before a fixed-time artificial insemination $\mathrm{CO}$-Synch + CIDR program in suckled beef cows. Theriogenology. 2014; 82: 104-113.

Meneghetti M, Sá Filho OG, Peres RFG, Lamb GC, Vasconcelos JLM. Fixed-time artificial insemination with estradiol and progesterone for Bos indicus cows I: Basis for development of protocols. Theriogenology. 2009; 72: 179-189.

Penteado L, Ayres H, Torres-Júnior JR, Souza AH, Baruselli PS. Taxa de concepção de vacas Nelore lactantes sincronizadas com dispositivo intravaginal de progesterona associado ao benzoato ou ao cipionato de estradiol. Acta Sci Vet. 2006; 34: 401.

Peres RFG, Claro Junior OG, Sá Filho OG, Nogueira GP, Vasconcelos JLM. Strategies to improve fertility in Bos indicus postpubertal heifers and nonlactating cows submitted to fixed-time artificial insemination. Theriogenology. 2009; 72: 681-689.

Pursley JR, Mee MO, Wiltbank MC. Synchronization of ovulation in dairy cows using PGF $2 \alpha$ and GnRH. Theriogenology. 1995; 44: 915-923.

Sá Filho MF, Reis EL, Viel JRJO, Nichi M, Madureira EH, Baruselli OS. Follicular dynamics in anestrous lactating Nellore cows treated with progesterone, eCG and GhRH. Acta Sci Vet. 2004; 235.

Sá Filho OG, Meneghetti M, Peres RFG, Lamb GC, Vasconcelos JLM. Fixed-time artificial insemination with estradiol and progesterone for Bos indicus cows II: Strategies and factors affecting fertility. Theriogenology. 2009;72: 210-218.

Sá Filho MF, Ayres H, Ferreira RM, Marques MO, Reis EL, Silva RCP, et al. Equine chorionic gonadotropin and gonadotropin-releasing hormone enhance fertility in a norgestomet based, timed artificial insemination protocol in suckled Nellore (Bos indicus) cows. Theriogenology. 2010; 73: 651658.

Sá Filho MF, Santos JEP, Ferreira RM, Sales JNS, Baruselli PS. Importance of estrus on pregnancy per insemination in suckled Bos indicus cows submitted to estradiol/progesterone-based timed artificial insemination protocols. Theriogenology. 2011; 76: 455-463.

Sales JNS, Crepaldi GA, Carvalho JBP, Girotto RW, Maio JRG, Rodrigues MP, et al. Momento da ovulação e taxa de concepção de vacas Nelore tratadas com diferentes fontes de cipionato ou de benzoato de estradiol para induzir a ovulação em protocolos de IATF. Acta Sci Vet. 2008; 36: 486.

Sales JNS, Carvalho JBP, Crepaldi GA, Cipriano RS, Jacomini JO, Maio JRG, et al. Effects of two estradiol esters (benzoate and cypionate) on the induction of synchronized ovulations in Bos indicus cows submitted to a timed artificial insemination protocol. Theriogenology. 2012; 78: 510-516.

Sales JNS, Carvalho JBP, Crepaldi GA, Soares JG, Girotto RW, Maio JRG, et al. Effect of circulating progesterone concentration during synchronization for fixed-time artificial insemination on ovulation and fertility in Bos indicus (Nellore) beef cows. Theriogenology. 2015; 83:1093-1100.

Short RE, Bellows RA, Staigmiller RB, Berardilnelli JG, Custer EE. Physiological mechanisms controlling anestrus and infertility in postpartum beef cattle. J Anim Sci. 1990; 68: 799-806.

Small JA, Colazo MG, Kastelic JP, Mapletoft RJ. Effects of progesterone presynchronization and eCG on pregnancy rates to GnRH-based, timed-AI in beef cattle. Theriogenology. 2009; 71: 698-706.

Soto Belloso E, Portillo Martinez De Ondiz A, Rojas N, Soto Castillo G, Ramirez Iglesia L, Perea Ganchou F. Improvement of reproductive performance in crossbred zebu anestrous primiparous cows by treatment with norgestomet implants or $96 \mathrm{~h}$ calf removal. Theriogenology. 2002; 57: 1503-1510. 
Wheaton JE and Lamb GC. Induction of cyclicity in postpartum anestrous beef cows using progesterone, GnRH and estradiol cypionate (ECP). Anim Reprod Sci. 2007; 102: 208-216.

Wiltbank MC, Gumen A, Sartori R. Physiological classification on anovulatory conditions in cattle.Theriogenology. 2002; 57: 21-52.
Yelich JV, Holland MD, Schutz DN, Odde KG. Synchronization of estrus in suckled postpartum beef cows with melengestrol acetate, $48 \mathrm{~h}$ calf removal and PGF2alpha. Theriogenology. 1995; 43: 401-410.

Received: July 27, 2015; Accepted: December 16, 2015. 